\title{
Synthesis of nanosized Al-HMS and its application in deep oxidation of benzene
}

\author{
Wei Zhao ${ }^{\mathrm{a}, \mathrm{b}}$, Jinjun $\mathrm{Li}^{\mathrm{b}}$, Chi He ${ }^{\mathrm{b}}$, Lina Wang ${ }^{\mathrm{a}}$, Jinlong Chu ${ }^{\mathrm{a}}$, Jinkui $\mathrm{Qu}^{\mathrm{a}}$, Tao $\mathrm{Qi}^{\mathrm{a}}$, Zhengping Hao $^{\mathrm{b}, *}$ \\ a Institute of Process Engineering, Chinese Academy of Sciences, Beijing 100190, China \\ ${ }^{\mathrm{b}}$ Research Center for Eco-Environmental Sciences, Chinese Academy of Sciences, Beijing 100085, China
}

\section{A R T I C L E I N F O}

\section{Article history:}

Available online 13 July 2010

\section{Keywords:}

Al-HMS

Catalytic combustion

Benzene

Pd

Nanostructures

\begin{abstract}
A B S T R A C T
High quality nanosize Al-HMS was successfully synthesized using ethanol as the co-solvent. Pd atoms could be highly dispersed on this nanosize support with ordered size of ca. $12 \mathrm{~nm}$. TEM studies revealed that support size could influence Pd dispersion behaviors greatly. Besides, frame Al of support also played some positive role on the catalytic activity of Pd-loaded catalyst. The complete conversion of benzene could be got at $200^{\circ} \mathrm{C}$ on this nanosize Pd/Al-HMS catalyst loaded only $0.9 \mathrm{wt} \% \mathrm{Pd}$ under high gas hourly space velocity of ca. $100000 \mathrm{~h}^{-1}$.
\end{abstract}

(C) 2010 Elsevier B.V. All rights reserved.

\section{Introduction}

Non-methane volatile organic compounds (VOCs) are primarily composed of four most-emitted groups (cyclic, aromatic, carbonyl and aliphatic hydrocarbon compounds) and a few amount of terpenoids and $\mathrm{N}$-containing compounds [1]. Usually, they are emitted from different sources, such as combustion byproducts, paints, and solvents. Now, more and more health and environment problems, for example, sick-building syndrome, formation of urban smog and ozone, ozone depletion and greenhouse, are recognized related to the VOCs [2]. Especially, benzene, toluene and xylene are the classification problem and belong to the group of the most dangerous air pollutant [3]. In order to efficiently control the VOCs emission, many techniques were employed, for instance, activated-carbon adsorption, catalytic oxidation, ozone oxidation, non-thermal plasma etc. [4]. Among them, the catalytic combustion was recognized as the most feasible and promising approach due to its high efficiency and low operation costs. The noble metalloaded materials and mixed metal oxides were widely used in VOCs elimination, while the noble metal-supported catalysts show much better activity than that of metal oxides and can be operated at much lower temperatures $\left(<300^{\circ} \mathrm{C}\right)[5]$. To obtain the cheap and stable catalyst, noble metal generally will be loaded on the supporting material to decrease the consuming of noble metal and increase the mechanic intensity [6]. Besides, the acidic/basic and textural properties of the support also possess some significant influences on the catalytic performances of the noble metal-loaded catalysts. Al-HMS mesoporous molecular sieve whose channel is rather

\footnotetext{
* Corresponding author.

E-mail addresses: tqi@home.ipe.ac.cn (T. Qi), zpinghao@rcees.ac.cn (Z. Hao).
}

wormhole-like than the straight channel like was first synthesized though a neutral templates route based on hydrogen bonding and self-assembling between neutral primary amine and neutral inorganic precursors [7]. It can be synthesized at ambient temperature in a short time and its template is cheap, commercially available and recyclable. Especially, unlike other mesoporous molecular sieves, Al-HMS with different $\mathrm{Si} / \mathrm{Al}$ ratios can be synthesized as easy as pure silica HMS under the similar preparation procedure. All of these provide Al-HMS as a good support for the preparation of industrial VOCs catalyst. In this paper, we synthesized the nanosize Al-HMS (50-60 $\mathrm{nm}$ ) by an improved hydrothermal synthesized method (just using ethanol as the co-solvent and sharply increasing the polarity of synthesis system) and loaded Pd on this nano-material. It was found that the metallic Pd can be highly dispersed on this support (ca. $12 \mathrm{~nm}$ ), while the similar phenomenon didn't happen on the sub-micrometer HMS. This nanosized Pd/Al-HMS catalyst showed excellent catalytic performance on the deep oxidation of benzene. The complete conversion of benzene could be got at $200^{\circ} \mathrm{C}$ on this novel catalyst loaded only $0.9 \mathrm{wt} \% \mathrm{Pd}$.

\section{Experimental}

\subsection{Catalyst preparation}

The tetraethyl orthosilicate (TEOS), dodecylamine (DDA), ethanol (EtOH) palladium chlorides and aluminum isopropoxide $\left(\mathrm{Al}\left(\mathrm{OBu}^{\mathrm{s}}\right)_{3}\right)$ were purchased from the No. 1 Chemical Reagent Company of Beijing. Deionized water was used throughout this study.

In a typical preparation, the mixture solution of TEOS, EtOH and $\mathrm{Al}\left(\mathrm{OBu}^{\mathrm{s}}\right)_{3}$ was added under vigorous stirring to a solution of DDA in ethanol and deionized water. The molar ratio of this synthesis mixture was $1.0 \mathrm{SiO}_{2}: x \mathrm{Al}\left(\mathrm{OBu}^{\mathrm{s}}\right)_{3}: 0.2-0.4 \mathrm{DDA}: 7-10 \mathrm{EtOH}: 142 \mathrm{H}_{2} \mathrm{O}$, 

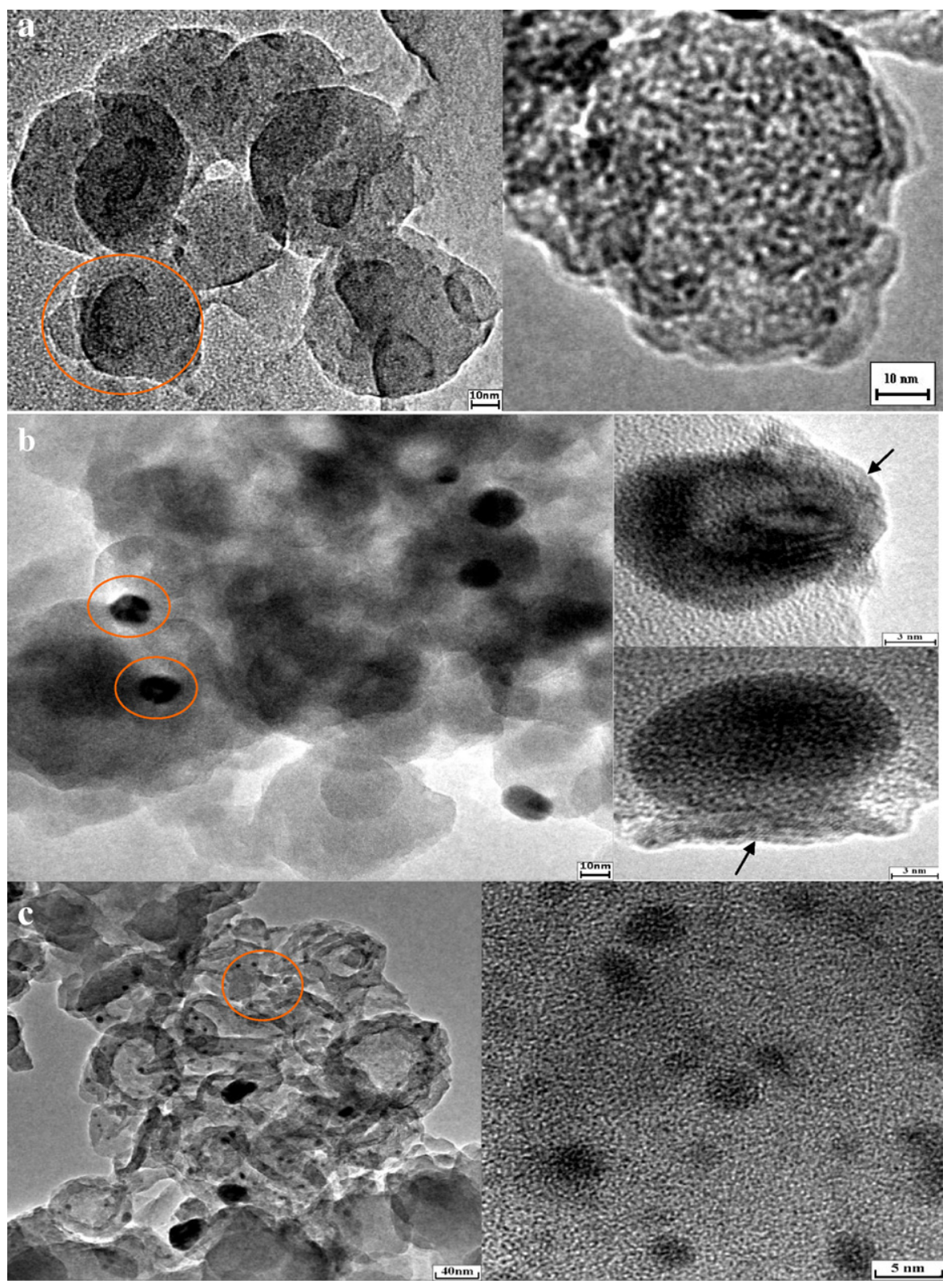

Fig. 1. The TEM images of different samples (the right side images are the enlarged images of the cycled part appearing in the left side images): $(\mathrm{a}) \mathrm{Al}-\mathrm{HMS}(\mathrm{Si} / \mathrm{Al}=50)$; $(\mathrm{b})$ Pd/Al-HMS (Si/Al = 50; 0.9 wt\% Pd); (c) Pd-HMS (0.9 wt\% Pd).
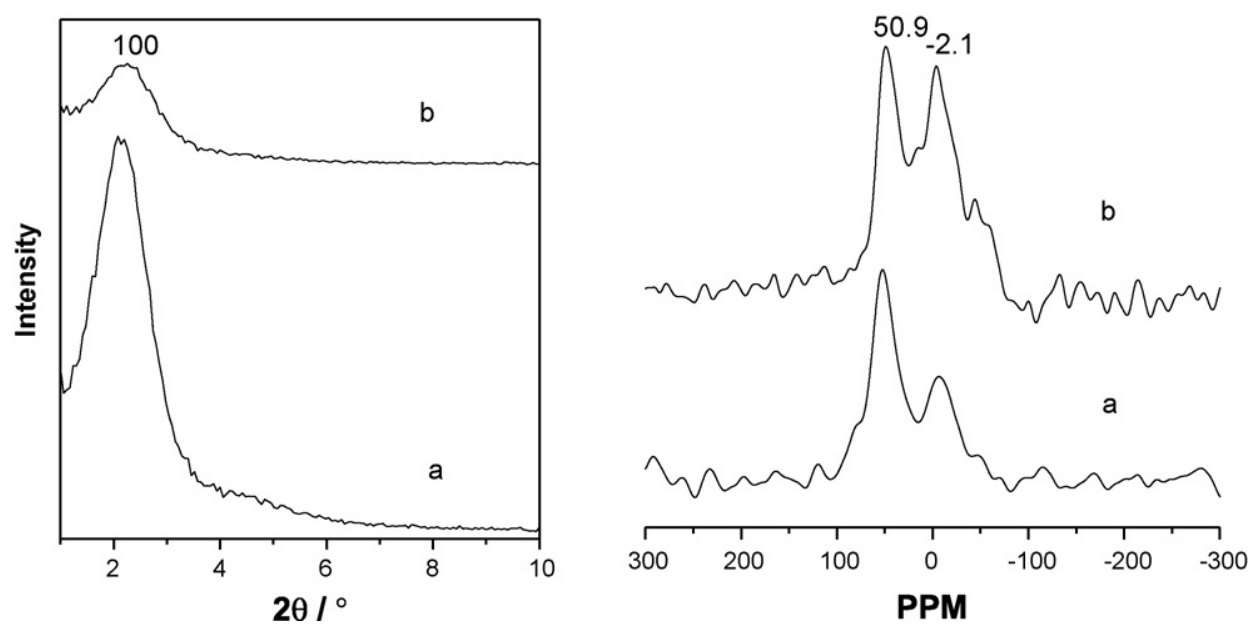

Fig. 2. The XRD (left) and ${ }^{27} \mathrm{Al}$ MAS NMR (right) spectrum of Al-HMS samples: (a) $\mathrm{Al}-\mathrm{HMS}$ ( $\mathrm{Si} / \mathrm{Al}=50$ ); (b) Pd/Al-HMS (Si/Al= 50; 0.9 wt\% Pd). 
where the value of $x$ is depend on various Si/Al ratios. This mixture was aged at ambient temperature for $24 \mathrm{~h}$. The as-synthesized Al-HMS were filtered, washed with $\mathrm{H}_{2} \mathrm{O}$, air-dried at $70^{\circ} \mathrm{C}$ and calcined in air at $550^{\circ} \mathrm{C}$ for $5 \mathrm{~h}$. Pd was loaded onto the Al-HMS via the aqueous impregnated method with palladium chlorides as precursor and the weight percent of palladium metal to the support was used as unit. The impregnated solids were calcined in air at $500^{\circ} \mathrm{C}$ for $3 \mathrm{~h}$ and then reduced in hydrogen at $400^{\circ} \mathrm{C}$ for $1 \mathrm{~h}$.

\subsection{Characterization}

Powder X-ray diffraction (XRD) patterns were collected on Bruker D5005 diffractometer using $\mathrm{Cu} \mathrm{K} \alpha$ radiation $(\lambda=1.5418 \AA$; $40 \mathrm{kV}$ and $40 \mathrm{~mA}$ ), Ni filter, scan speed $4 \% \mathrm{~min}$. High-resolution TEM (HRTEM) images were recorded on a H-9000NAR electron microscope operated at $300 \mathrm{kV}$. The solid-state ${ }^{27} \mathrm{Al}$ MAS NMR spectra were recorded at room temperature on a Varian INOVA300 spectrometer with resonance frequencies of $78.16 \mathrm{MHz}$. The spin rate of the sample was $7.0 \mathrm{KHz}$ and the chemical shifts were referenced to $\mathrm{AlCl}_{3} \cdot 6 \mathrm{H}_{2} \mathrm{O}$. Temperature-programmed reduction (TPR) was performed for all the catalysts on a conventional TPR apparatus equipped with a thermal conductivity detector (TCD). Prior to each TPR run, the catalyst $\left(50 \mathrm{mg}\right.$ ) was pretreated at $30^{\circ} \mathrm{C}$ under an $\mathrm{N}_{2}$ flow $\left(30 \mathrm{ml} / \mathrm{min}\right.$ ) for $1 \mathrm{~h}$. The catalyst was then heated to $400{ }^{\circ} \mathrm{C}$ at a constant heating rate of $10^{\circ} \mathrm{C} / \mathrm{min}$ using $\mathrm{H}_{2}$ ( $\left.5 \mathrm{vol} \%\right) / \mathrm{N}_{2}$ (95 vol\%) under a flow rate of $30 \mathrm{ml} / \mathrm{min}$. $\mathrm{H}_{2}$ concentration was monitored by the TCD detector. Nitrogen adsorption/desorption isotherms were obtained on a NOVA1200 gas sorption analyzer. The mesopore size distributions were derived from the desorption branch of the $\mathrm{N}_{2}$ isotherms using the Barrett-Joyner-Halenda (BJH) method. The total pore volumes were estimated from the amount of nitrogen adsorbed at a relative pressure $\left(P / P_{0}\right)$ of ca. 0.99 .

\subsection{Catalytic combustion reaction}

Just did as Ref. [6], catalytic activity tests were performed in a continuous-flow fixed-bed reactor of $6 \mathrm{~mm}$ i.d using $0.1 \mathrm{~g}$ catalyst. To create the stream containing $1050 \mathrm{ppm}$ benzene, one stream of pure air was passed through a boat-shape saturator in an ice-bath to get a mixed gas containing high concentration benzene and then it was diluted with another stream of pure air before reaching the catalyst bed. The gas hourly space velocity (GHSV) in the tests was kept ca.100 $000 \mathrm{~h}^{-1}$. An on-line gas chromatograph equipped with FID detector was used to analyze the concentration of benzene in the inlet and outlet gas.

\section{Results and discussion}

\subsection{Characterization of the materials}

Fig. 1 is the TEM images of Al-HMS (Fig. 1(a)), Pd/Al-HMS (Fig. 1(b)) and Pd/HMS (Fig. 1(c)). All the samples are the high quality HMS with the wormhole-like framework (see the right part figures). Among them, Al-HMS sample is composed of nanosize particles with the size ca.50-60 nm (Fig. 1(a), left). And the metallic Pd is dispersed to the uniform $12 \mathrm{~nm}$ particles (Fig. 1(b), left) on this support. It is interesting to note that the Pd particles prefer to lie on the edge of this support. Under the high magnification, the (111) crystal plane of Pd (Fig. 1(b), right, as the arrow shown) can be observed clearly. Unlike the order Pd particles forming on the nano Al-HMS, the Pd shows two different dispersion behaviors on submicrometer HMS. Parts of them are encapsulated inside the pore of support (Fig. 1(c), right), while others aggregate to form the big particles with the size of $40 \mathrm{~nm}$ out of the channel (Fig. 1(c), left). The forming of ordered Pd particles on the nano Al-HMS probably can be ascribed to the large extra-surface (more adsorbed sites)

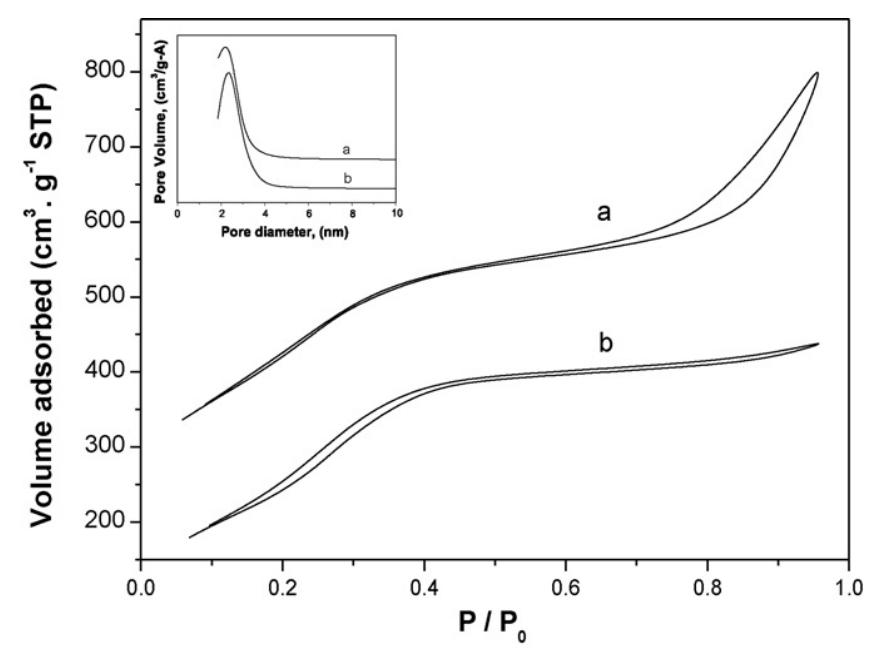

Fig. 3. The $\mathrm{N}_{2}$ adsorption-desorption isotherms of different samples: (a) Pd/Al-HMS ( $\mathrm{Si} / \mathrm{Al}=50 ; 0.9 \mathrm{wt} \% \mathrm{Pd}$ ); (b) Pd/HMS (0.9 wt\% Pd).

and regular spherical morphology of nanosize Al-HMS. So, Pd can be dispersed easily on the extra-surface along the fringe of Al-HMS particles before they diffuse into Al-HMS channel. In addition, since the higher surface curvature and the existing of Al atom, both the surface flowability and surface polarity of nanosize Al-HMS will be higher than that of sub-micron-sized HMS. Palladium chlorides are an inorganic palladium precursor. They will have a higher solubility on the more polarity surface of nanosize Al-HMS. Together with other factors, for example, the chemical energy at the interface, the special support environment of nanosize Al-HMS, small size (12 nm) Pd particles will be advantaged to form.

Fig. 2 displays the XRD (left) and NMR (right) spectrum of AlHMS samples. It can be observed that the $\left(\begin{array}{lll}1 & 0 & 0\end{array}\right)$ peak intensity of $\mathrm{Pd} / \mathrm{Al}-\mathrm{HMS}$ sample decreases sharply compared to that of pure AlHMS support. It means that the long-range structure order of AlHMS is somewhat decreased (this is in good responding to the result of TEM). The morphology of Al-HMS becomes some disorder after the incipient procedure (Fig. 1(a) and (b), left). The NMR results (Fig. 2, right) give us some explanation for this change. It was found that the signal of extra-framework aluminum ( $-2.1 \mathrm{ppm})$ for Pd/AlHMS sample increases obviously compared to the pure Al-HMS. It suggests that some $\mathrm{Al}^{3+}$ ions may escape from the framework of Al-HMS during the incipient procedure. As a result, the textural uniformity of Al-HMS will be undermined inevitably.

Fig. 3 is the $\mathrm{N}_{2}$ adsorption-desorption isotherms of Pd/Al-HMS and Pd/HMS samples. Both of the samples have a well-defined step in the adsorption curve between partial $P / P_{0}$ of 0.15 and 0.45 . The appearance of this step is indicative of the filling of frameworkconfined mesoporous (Fig. 3, inset). In the region of $P / P_{0}>0.6$, there exists a larger hysteresis loop of Pd/Al-HMS sample compared to that of Pd/HMS sample. It indicates some fundament particles of Al-HMS will aggregate to forming the textural mesoporosity (there exists a white color cavity among the aggregative particles in Fig. 1(a), left) and this hysteresis loop is corresponding to the inter-particle capillary condensation. From Table 1, we can observe that both the specific surface area and pore volume of Al-HMS are higher than those of HMS. However, the pore diameter of Al-HMS is some smaller than that of HMS. After the impregnated procedure, both specific surface area and pore diameter of these two samples just decrease slightly $(<5 \%)$, while the pore volume of Al-HMS decrease about $26.4 \%$ in contrast to the $8.2 \%$ of HMS. The sharply decrease of pore volume for Al-HMS sample is caused by that some $\mathrm{Al}^{3+}$ ions escape from the framework (Fig. 2(b), right) and that some inter-particle pores are damaged (Fig. 1(b), left). 
Table 1

Textural properties of synthesized materials.

\begin{tabular}{lcll}
\hline Samples & $\begin{array}{l}\text { BET surface } \\
\text { area }\left(\mathrm{m}^{2} / \mathrm{g}\right)\end{array}$ & $\begin{array}{l}\text { Pore volume } \\
\left(\mathrm{cm}^{3} / \mathrm{g}\right)\end{array}$ & Pore size $(\AA)$ \\
\hline Al-HMS & 1064.4 & 1.10 & 22.8 \\
HMS & 945.9 & 0.73 & 23.5 \\
Pd/Al-HMS & 1008.1 & 0.81 & 22.1 \\
Pd/HMS & 927.3 & 0.67 & 23.3 \\
\hline
\end{tabular}

a $\mathrm{Si} / \mathrm{Al}=50$.

b $\mathrm{Si} / \mathrm{Al}=50$, Pd loading is $0.9 \mathrm{wt} \%$.

c Pd loading is $0.9 \mathrm{wt} \%$.

\subsection{Catalytic oxidation activity}

The catalytic performances for the deep oxidation of benzene based on different materials were shown in Table 2. For the same Pd loading ( $0.9 \mathrm{wt} \%)$, the activity sequence of different supports is: Al-HMS $>\mathrm{HMS}>\mathrm{Al}_{2} \mathrm{O}_{3}$. Together with that Al-HMS itself also has $6.1 \%$ activity, we thought the acid of framework $\mathrm{Al}$ is advantaged to the Pd catalyst. In addition, the activity of Pd/Al-HMS catalyst is almost three times higher than that of Pd/sub-micrometer HMS catalyst. We could explain this result from following four aspects. Firstly, just as we discussed above, some Pd particles of Pd/HMS catalyst are introduced into the channel of support. So, benzene needs to enter the channel and contact with activity sites (Pd) here. On the contrary, for Pd/Al-HMS catalyst, most of Pd particles are lie on the extra-surface. So, benzene can contact with these Pd particles quickly. Secondly, the increase of extra-surface Pd particle density will raise the probability of efficiency elastic collision. As a result, the reaction rate will accelerate correspondingly. Thirdly, Yoshida and co-workers [8] had reported that acidic support can provides Pd the resistibility against oxidation during reaction procedure, and then, the metallic Pd can be kept under the air atmosphere. Fourthly, deep oxidation of benzene is an exothermic reaction and the activity of Pd catalyst is very sensitive to temperature variation. Thus the thermal conductivity of support will play some role on catalytic activity too. Under $200^{\circ} \mathrm{C}$, thermal conductivity of aluminum oxide is much higher than that of silica and the value is almost invariable [9]. So, the Al-HMS can transmit the heat more quickly compared to pure-HMS, and then, the reaction equation will shifts to deep oxidation. In addition, high thermal conductivity also is helpful to prevent activity centres from the excess heat in this location.

Learning from Table 2, we also found: as the Pd loading of $\mathrm{Pd} / \mathrm{Al}-\mathrm{HMS}(\mathrm{Si} / \mathrm{Al}=50)$ catalyst increase from $0.9 \mathrm{wt} \%$ to $1.2 \mathrm{wt} \%$, the catalytic activity does not enhance correspondingly. Based on the TPR results (Fig. 4), we found the TCD signals are similar for Pd/Al-HMS (0.6wt\% Pd) and Pd/Al-HMS (0.9wt\% Pd) sample. There are two negative peaks below $160^{\circ} \mathrm{C}$. However, for Pd/AlHMS (1.2 wt\% Pd) sample, the second negative peak shifts to the

Table 2

Catalytic performances of different catalysts.

\begin{tabular}{llc}
\hline Catalyst & Pd loading $(w t \%)$ & $\begin{array}{l}\text { The conversion of } \\
\text { benzene at } 200{ }^{\circ} \mathrm{C}(\%)\end{array}$ \\
\hline $\mathrm{HMS}$ & 0 & 0 \\
$\mathrm{HMS}$ & 0.9 & 33.8 \\
$\mathrm{HMS}$ & 1.5 & 78.1 \\
$\mathrm{Al}_{2} \mathrm{O}_{3}$ & 0.9 & 17.6 \\
$\mathrm{Al}-\mathrm{HMS}(\mathrm{Si} / \mathrm{Al}=50)$ & 0 & 6.1 \\
$\mathrm{Al}-\mathrm{HMS}(\mathrm{Si} / \mathrm{Al}=50)$ & 0.6 & 65.4 \\
$\mathrm{Al}-\mathrm{HMS}(\mathrm{Si} / \mathrm{Al}=50)$ & 0.9 & 99.6 \\
$\mathrm{Al}-\mathrm{HMS}(\mathrm{Si} / \mathrm{Al}=50)$ & 1.2 & 89.3 \\
$\mathrm{Al}-\mathrm{HMS}(\mathrm{Si} / \mathrm{Al}=100)$ & 0.9 & 97.2 \\
$\mathrm{Al}-\mathrm{HMS}(\mathrm{Si} / \mathrm{Al}=20)$ & 0.9 & 87.8 \\
\hline
\end{tabular}

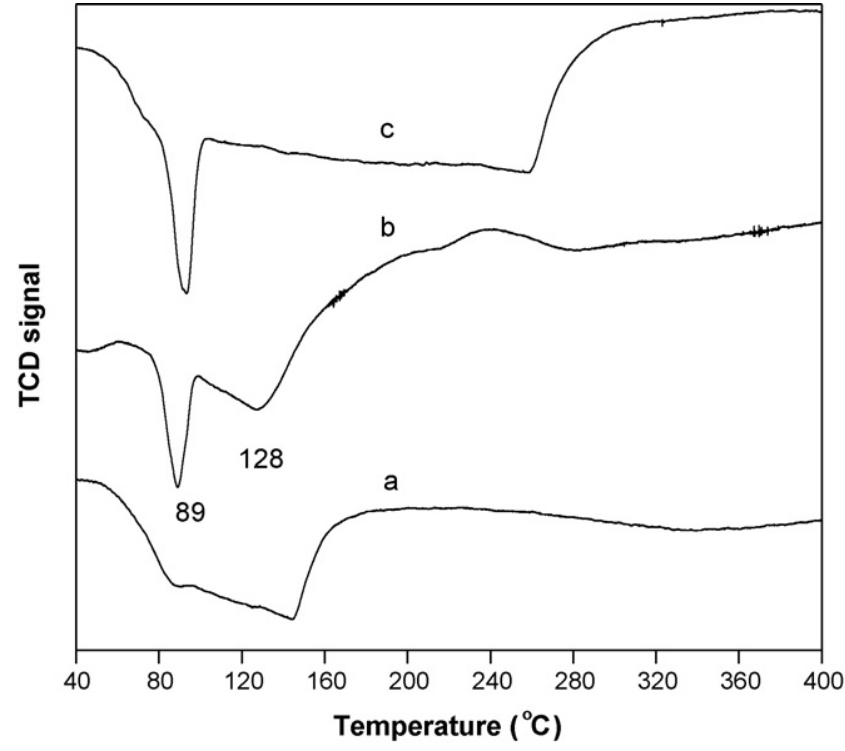

Fig. 4. TPR profiles of different catalysts: (a) Pd/Al-HMS ( $\mathrm{Si} / \mathrm{Al}=50 ; 0.6 \mathrm{wt} \% \mathrm{Pd}$ ); (b) Pd/Al-HMS (Si/Al = 50; 0.9 wt\% Pd); (c) Pd/Al-HMS (Si/Al = 50; 1.2 wt\% Pd).

high temperature region sharply $\left(245^{\circ} \mathrm{C}\right)$. The first negative peak (around $90^{\circ} \mathrm{C}$ ) usually corresponds to the decomposition of bulk Pd hydride $(\beta-\mathrm{PdH})$ that is caused by the adsorption of hydrogen on metallic Pd [10] (just like the physic absorption). While the second negative peak are attributed to the decomposition of $\beta-\mathrm{PdH}_{x}[11]$ that is probably related to the various mixed phase of $\mathrm{Pd}^{0} / \mathrm{PdO}_{x}$ or the agglomeration degree of Pd particles (just like the chemical adsorption). When the Pd loading increases from $0.9 \mathrm{wt} \%$ to $1.2 \mathrm{wt} \%$, the results of XRD and $\mathrm{N}_{2}$ sorption showed that the textural property of support do not change significantly. Consequently, it is the difference of activity sites that cause the decrease of catalytic activity. Based on the above TPR result, we knew that the $\beta-\mathrm{PdH}_{x}$ of Pd/Al-HMS (1.2 wt\% Pd) cannot release the metallic Pd completely until at $245^{\circ} \mathrm{C}$. So, if the reaction temperature is below $245^{\circ} \mathrm{C}$, only part activity sites (Pd) of Pd/Al-HMS (1.2 wt\% Pd) catalyst would play the role. As a result, its catalytic activity will be some lower than that of Pd/Al-HMS (0.9 wt\% Pd) catalyst.

Keeping the Pd loading constantly, when the Si/Al of Al-HMS samples change, there exist an optimum value $(\mathrm{Si} / \mathrm{Al}=50)$ too. From Table 2, we can see that the activity of Pd/Al-HMS ( $\mathrm{Si} / \mathrm{Al}=100)$ is almost same as that of Pd/Al-HMS $(\mathrm{Si} / \mathrm{Al}=50)$ and the activity of $\mathrm{Pd} / \mathrm{Al}-\mathrm{HMS}(\mathrm{Si} / \mathrm{Al}=20)$ is just $12.2 \%$ less than that of Pd/Al-HMS $(\mathrm{Si} / \mathrm{Al}=50)$. In other word, the activity difference among these three $\mathrm{Pd} / \mathrm{Al}-\mathrm{HMS}$ samples is insignificant although Pd/Al-HMS $(\mathrm{Si} / \mathrm{Al}=50)$ sample is the best one. Based on Fig. 5, we can see that the XRD diffraction peaks of $\mathrm{Al}-\mathrm{HMS}(\mathrm{Si} / \mathrm{Al}=20)$ are much weaker than that of other two samples. However, the ratio between framework aluminum and extra-framework aluminum of $\mathrm{Al}-\mathrm{HMS}(\mathrm{Si} / \mathrm{Al}=20)$ is obvious higher than that of other two Al-HMS samples. So, which one is the main reason causing the $12.2 \%$ activity difference? Actually, our above results (The activity sequence of different supports is: Al-HMS $>\mathrm{HMS}>\mathrm{Al}_{2} \mathrm{O}_{3}$ ) and former report (the extraframework aluminum is easy to decompose to $\mathrm{Al}_{2} \mathrm{O}_{3}$ that will decrease the activity of $\mathrm{Pd}$ by forming the $\mathrm{PtO}_{2}-\mathrm{Al}_{2} \mathrm{O}_{3}$ complex [12]) prove that framework aluminum is more advantaged than extra-framework aluminum for this reaction. So, we thought the poor textural uniformity of Al-HMS $(\mathrm{Si} / \mathrm{Al}=20$ ), which is harmful to the diffusion speed of substrate and products, is the main factor inducing the activity decrease. Although the Si/Al ratio is different of $\mathrm{Pd} / \mathrm{Al}-\mathrm{HMS}(\mathrm{Si} / \mathrm{Al}=100)$ and $\mathrm{Pd} / \mathrm{Al}-\mathrm{HMS}(\mathrm{Si} / \mathrm{Al}=50)$, the 

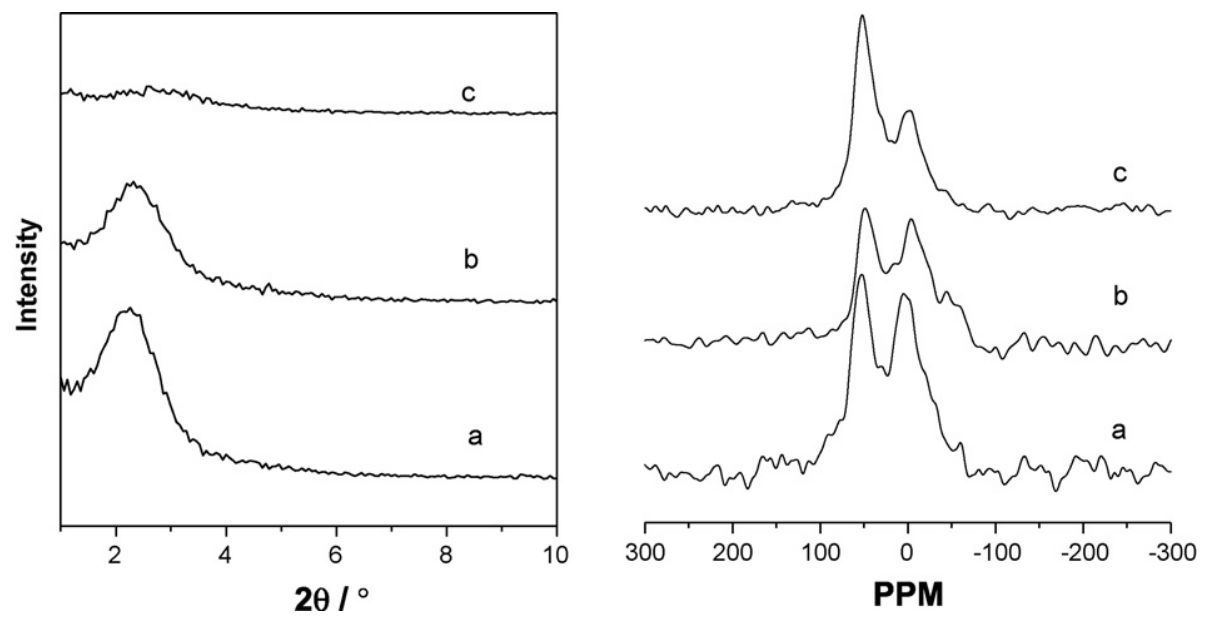

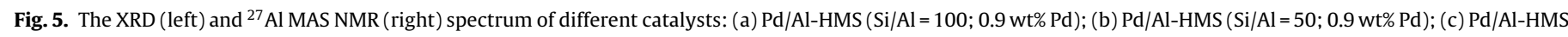
$(\mathrm{Si} / \mathrm{Al}=20 ; 0.9 \mathrm{wt} \% \mathrm{Pd})$.

XRD pattern and NMR signal of these two samples are similar. It means that their support environment have not obvious difference, as a result, the catalytic activity of these two catalysts is very close.

For studying the stability of obtained catalyst, we reduced the used sample (Pd/Al-HMS ( $\mathrm{Si} / \mathrm{Al}=50 ; 0.9 \mathrm{wt} \% \mathrm{Pd})$ ) in situ (The catalyst need not to be taken out of reactor) in hydrogen at $400^{\circ} \mathrm{C}$ for $1 \mathrm{~h}$ and then did the next test. It was found that the catalyst keeps its activity even after 10 successive cycles.

\section{Conclusions}

Nanosize Al-HMS was successfully synthesized under high polarity hydrothermal system. Pd can be highly dispersed to the order $12 \mathrm{~nm}$ on this support. Both the nanosize and the frame aluminum of support play the important role on the catalytic performance of Pd catalysts. The catalyst that has the $\mathrm{Si} / \mathrm{Al}=50$ with the Pd loading of $0.9 \mathrm{wt} \%$ showed the best performances on the catalytic combustion of benzene. We believe this newly developed catalyst will have bright application prospects in the practical controlling of the VOCs emission.

\section{Acknowledgments}

We are grateful for the support of National Basic Research Program of China (2007CB613501 and 2010CB732300), National Key Technologies R\&D Program (2006BAC02A05 and 2006AA06A310) and National Natural Science Foundation (20725723).

\section{References}

[1] R. Rinnan, A. Rinnan, T. Holopainen, J.K. Holopainen, P. Pasanen, Atmos. Environ. 39 (2005) 921.

[2] T. Sano, N. Negishi, K. Takeuchi, S. Matsuzawa, Solar Energy 77 (2004) 543.

[3] A. Szczurek, M. Maciejewska, Talanta 64 (2004) 609.

[4] S. Futamura, A. Zhang, H. Einaga, H. Kabashima, Catal. Today 72 (2002) 259.

[5] J.J. Li, Z. Jiang, Z.P. Hao, X.Y. Xu, Y.H. Zhuang, J. Mol. Catal. A 225 (2004) 173.

[6] J.J. Li, X.Y. Xu, Z. Jiang, Z.P. Hao, C. Hu, Environ. Sci. Technol. 39 (2005) 1319.

[7] P.T. Tanev, T.J. Pinnavaia, Science 267 (1995) 865.

[8] Y. Yazawa, H. Yoshida, N. Takagi, S. Komai, A. Satsuma, T. Hattori, J. Catal. 187 (1999) 15.

[9] G.V. Samsonov, The Oxide Handbook, second ed., IFI/Plenum Data Company, New York, 1982, pp. 110-120 (Chapter II).

[10] L.M. Gómez-Sainero, X.L. Seoane, J.L.G. Fierro, A. Arcoya, J. Catal. 209 (2002) 279.

[11] S.C. Shekar, K.S.R. Rao, E.S. Demessie, Appl. Catal. A: Gen. 294 (2005) 235.

[12] H.C. Yao, M. Sieg H.K.Jr., Plummer, J. Catal. 59 (1979) 365. 